400

\author{
WAPD-TM-207 \\ AEC RESEARCH AND \\ DEVELOPMENT REPORT
}

\title{
CLIP 1 - AN IBM-704 PROGRAM TO SOLVE THE P-3 EQUATIONS IN CYLINDRICAL GEOMETRY
}

MAY 1962

CONTRACT AT-11-1-GEN-14

BETTIS ATOMIC POWER LABORATORY PITTSBURGH, PENNSYLVANIA

Operated for the

v

U.S. ATOMIC ENERGY COMMISSION bY WESTINGHOUSE

ELECTRIC CORPORATION 


\section{DISCLAIMER}

This report was prepared as an account of work sponsored by an agency of the United States Government. Neither the United States Government nor any agency Thereof, nor any of their employees, makes any warranty, express or implied, or assumes any legal liability or responsibility for the accuracy, completeness, or usefulness of any information, apparatus, product, or process disclosed, or represents that its use would not infringe privately owned rights. Reference herein to any specific commercial product, process, or service by trade name, trademark, manufacturer, or otherwise does not necessarily constitute or imply its endorsement, recommendation, or favoring by the United States Government or any agency thereof. The views and opinions of authors expressed herein do not necessarily state or reflect those of the United States Government or any agency thereof. 


\section{DISCLAIMER}

Portions of this document may be illegible in electronic image products. Images are produced from the best available original document. 


\section{CLIP 1 - - AN IBM-704 PROGRAM TO SOLVE THE P-3 EQUATIONS IN CYITNDRICAL GEOMEIRY}

B. Anderson, Jo Davis, E. Gelbard, $P_{0}$.Jarvis, and Jo Pearson

Contract $A T-11-I-G E N-14$

May 1962

Price $\$ .50$

Available from the Office of Technical Services,

Department of Commerce, Washington $25, \mathrm{D} . \mathrm{C}$ 。

This document is an internal memorandum prepared primarily for internal reference and does not represent a final expression of the opinion of Westinghouse. When this memorandum is distributed externally, it is with the express understanding that Westinghouse makes no representation. as to completeness, accuracy, or usability of information contained therein.

BETTIS ATOMIC POWER IABORATORY .: PITTSBURGH, PENNSYLVANIA

Operated for the U. S. Atomic Energy Commission by Westinghouse Electric Corporation 
UC-32: Mathematics and Computers, TID-4500, 17th Edition

SPECIAI EXTERNAL DISTRIBUTION

Director, Development Division, PNRO

Argonne National Laboratory, W. F. Miller Brookhaven National laboratory, J.:Chernick

Case Institute of Technology, R. S. Varga

David Taylor Model Basin, H. Polachek

Knolls Atomic Power Laboratory, R. Ehrlich

Ios Alamcs Scientific Iaboratory, B。 Carlson

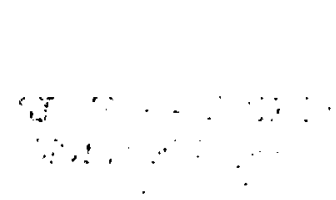

New York University, R. Richtmyer

Oak Ridge National Laboratory, A. Househoider

Union Carbide Nuclear Company, K-25, V. E. Anderson

University of California Radiation Laboratory, Livermore, S. Fernbech

This report was prepared as an account of Government sponsored work. Neither the United States, nor the Commission, nor any person acting on behalf of the Commission:

A. Makes any werranty or representation, expressed or implied; with respect to the accuracy, completeness, or usefulness of the information contained in this report, or that the use of any information, apparatus, method, or process disclused in this .... . report may not infringe privately owned rights; or

B. Assumes any liablilties with respect to the use of or for damages resulting from the use of any information; apparatus, method, or process disclosed in this report.

As used in the cicove, "person acting on behalf of the Comission" includes any employe or contractor of the Commission, or employe of such contractor, to the extent that such employe or contractor of the Commission, or employe of such contractor prepares, disseminates, or provides access to, any information pur-. suant to his employment or contract with the Commission, or his employment with such contractor. 
A second order form of the cylindrical $\mathrm{P}-3$ equations is obtained for the case of an isotropic source. The boundary conditions and numerical method are aiscussed. Input preparation and operating instructions are included.

\author{
CLIP 1 - AN IEM-704 PROGRAM TO SOLVE THE \\ P-3 EQUATIONS IN CYLINDRICAL CEONETRY \\ P. Ande:son, Jo Davis, E. Gelbard, \\ $P$. Jarvis, and J. Pearson
}

\title{
I. INTRODUCTION
}

CLIP is designed to soive the ore velosity transport equation in orie dimensional cylindrical geometry in a F-3 approximation. The P-3 equations are solved iteratively with the aid of standard finite difrerencing techniques. Anisotropic scattering is permitted, within the limitations of $\mathrm{p}-3$, but the input source must be isotropic. Zero fiux or zero gracient, bourdery conditions are avallable as options, and as a consequence of the method of solvtion, a P-I solution can be obtained. CIIP is restricted to $a$ maximum oi 50 reglons aad 501 mesh points.

\section{EQUATIONS AND METTOD OF SOIUTION}

Fleck's (Ref 1) formuletion of a P-3 apprcximation to the one-velocity transport equation in one-dimensional eylinarical geometry leads to a set of six linear first order differential equetions, which may be witten as

$$
\begin{gathered}
\left(\frac{d}{d r}+\frac{l}{r}\right) \psi_{3}+\Sigma_{0} \psi_{0}=s \\
\frac{d}{d r} \psi_{0}-\frac{d}{d r} \psi_{1}+\left(\frac{d}{d r}+\frac{2}{r}\right) \psi_{2}+3 \Sigma_{1} \psi_{3}=0 \\
3\left(\frac{d}{d r}+\frac{1}{r}\right) \psi_{4}-\left(\frac{d}{d r}+\frac{1}{r}\right) \psi_{3}+5 \Sigma_{2} \psi_{1}=0 \\
2 \frac{d}{d r} \psi_{1}-\frac{1}{3}\left(\frac{d}{d r}+\frac{2}{r}\right) \psi_{2}+7 \Sigma_{3} \psi_{4}=0
\end{gathered}
$$




$$
\begin{array}{r}
\frac{3}{2}\left(\frac{d}{d r}+\frac{3}{r}\right) \psi_{5}+3\left(\frac{d}{d r}-\frac{1}{r}\right) \psi_{3}-\frac{3}{2}\left(\frac{d}{d r}-\frac{1}{r}\right) \psi_{4}+5 \Sigma_{2} \psi_{2}=0 \\
5\left(\frac{d}{d r}-\frac{2}{r}\right) \psi_{2}+7 \Sigma_{3} \psi_{5}=0
\end{array}
$$

where, in terms of Fleck's notation (on the rightahand side)

$$
\begin{aligned}
& \psi_{0}=\psi(0) \\
& \psi_{1}=\psi^{11} \\
& \psi_{2}=\psi^{11}+2 \psi^{33} \\
& \psi_{3}=\psi^{3} \\
& \psi_{4}=\psi^{113} \\
& \psi_{5}=3 \psi^{113}+4 \psi^{333}
\end{aligned}
$$

and where $S$ is the isotropic source, and $\Sigma_{1}=\Sigma_{a}+\Sigma_{s 0}-\Sigma_{s 1}(i=0,1,2,3)$. Here $\Sigma_{\mathrm{a}}$ is the absorption cross section, and $\Sigma_{\mathrm{gl}}$ is the foth Legendre component of the scattering cross section. $\psi_{0}$ and $\psi_{3}$ are simply the scalar flux and the outward going radial current respectively.

The relations between the moments appearing in CLIP 1 and those appearing in BOUND ${ }^{*}$ (Ref 2) are as follows:

$$
\begin{array}{ll}
\psi_{0}=\varphi_{0,0} & \Psi_{3}=\varphi_{1,1 .} . \\
\psi_{1}=\varphi_{2,0} & \psi_{2}=\frac{1}{2} \varphi_{2,2} . \\
\psi_{4}=\frac{1}{3} \varphi_{3,1} & \psi_{5}=\frac{1}{6} \varphi_{3,3}
\end{array}
$$

Now by means of a few simple substitutions, Eqs (1) through (6) can be written respectively as,

$$
\begin{gathered}
\left(\frac{d}{d r}+\frac{l}{r}\right) \psi_{3}+\Sigma_{a} \psi_{0}=s \\
\frac{d \psi_{0}}{d r}+3 \Sigma_{2} \psi_{3}=\frac{d \psi_{1}}{d r}-\left(\frac{d}{d r}+\frac{2}{r}\right) \psi_{2}
\end{gathered}
$$

BOUND is an IBM-704 program in which the analytic solution for the moments is evaluated at discrete points. 


$$
\begin{aligned}
& 3\left(\frac{d}{d r}+\frac{l}{r}\right) \psi_{4}+5 \Sigma_{2} \psi_{I}=S-\Sigma_{a} \psi_{0} \\
& \frac{5}{3} \frac{d v_{1}}{d r}+7 \Sigma_{3} \psi_{4}=-\frac{1}{3} \frac{d \psi_{0}}{d r}-\Sigma_{1} \psi_{3} \\
& \frac{3}{4}\left(\frac{d}{d r}+\frac{3}{r}\right) \psi_{5}+\frac{5}{2} \Sigma_{2} \psi_{2}=s-\Sigma_{a_{2}} \psi_{0}+\frac{3}{4}\left(3 \frac{d}{d r}+\frac{2}{r}\right) \psi_{4}-3 \frac{d \psi_{3}}{d r}+\frac{5}{2} \Sigma_{2} \psi_{1} \\
& \frac{5}{4}\left(\frac{d}{d r}-\frac{2}{x}\right)_{2}+\frac{7}{4} \Sigma_{3} \psi_{5}=0
\end{aligned}
$$

If now the values of $\psi_{3}, \psi_{4}$, and. $\psi_{5}$ as determined by Eq (8), (10), and (12) are inserted into Eq (7), (9), disc (11) then the following second order equations result.

$$
-D_{j}\left(\frac{d^{2}}{d r^{2}}+\frac{I}{j} \frac{d}{d r}\right) \psi_{i}+\Sigma_{T i} \psi_{i}=s_{i} \quad(i=0, I, 2)
$$

where, $D_{0}=\frac{1}{3 \Sigma_{1}}$

$$
\begin{aligned}
& \Sigma_{\text {no }}=\Sigma_{0} \\
& \Sigma_{r_{1} I}=5 \Sigma_{2} \\
& \Sigma_{\mathrm{T} I}=\frac{5}{2} \Sigma_{2}+\frac{1}{r^{2}}\left(\frac{16}{5} \mathrm{D}_{1}+6 \mathrm{D}_{0}\right) \\
& S_{0}=S-D_{0}\left[\left(\frac{d^{2}}{d r^{2}}+\frac{1}{r} \frac{d}{d r}\right) \psi_{1}-\left(\frac{d^{2}}{d r^{2}}+\frac{3}{r} \frac{d}{d r}\right) \psi_{2}\right] \\
& s_{2}=-\frac{5}{4} s+\frac{5}{4} \Sigma_{0} \psi_{0}-\frac{3}{2} \frac{D_{0}}{r} \frac{d \psi_{0}}{d r}-\frac{\Sigma_{1}}{1} \|_{1}+\left(\frac{3}{5} n_{1}+3 n_{0}\right) \frac{1}{r} \frac{d \Psi_{1}}{d r}-\left(\frac{D_{1}}{10}+3 n_{0}\right) \frac{1}{r} \frac{d \Psi_{2}}{d r}
\end{aligned}
$$$$
\mathrm{D}_{1}=\frac{5}{7 \Sigma_{3}}
$$$$
D_{2}=\frac{3}{4} D_{2}
$$$$
S_{1}=\left(I+\frac{D_{1}}{D_{0}}\right) S-\frac{D_{I}}{D_{0}} S_{0}-\Sigma_{a} \psi_{0}
$$

Equations (13) are solved iteratively in CLIP I according to the following procedure: Assume that $\psi_{1}^{k}$ and $\psi_{2}^{k}$ are available where the superscript $k$ denotes the $k-t h$ iterate solution. $s_{0}^{k}$ is constructed from $\psi_{j}^{k}$ and $\psi_{2}^{k}$ and a solution obtained for $\psi_{0}$ which we denote as $\psi_{0}^{k}$. Then $s_{1}^{k+1}$ is formed from $s_{0}^{k}$ and $\psi_{0^{2}}^{k}$ and $\psi_{1}^{k+1}$ is determined.

3 
Next $S_{2}^{k+1}$ is constructed from $\psi_{0}^{k}, \psi_{1}^{k+1}, \psi_{2}^{k}$ and a new solution is obtained for $\psi_{2}$ which in our notation is $\psi_{2}^{k+1}$. Now $\psi_{1}^{k+1}$ and $\psi_{2}^{k+1}$ are available and the process can be repeated. The iterative process is initiated in CLIP by taking $\psi_{1}^{1}=\psi_{2}^{1}=0$; hence $\psi_{0}^{I}$ is the P-I solution. Thus subsequent iterates make corrections to the P-I solution. If the P-I solution were not very different from the P-3 solution, one might expect that the process would converge in a few iterations, and conversely, if the P-I solution were very difierent from the $\mathrm{P}-3$ then the process might require a larger number of iterations. In practice, the number of iterations required to satisfy a specific convergence criteria on CIIP ranges from 8-12 as compared to 4-8 for an equivalent problem on FLIP (Ref 3).

At the conclusion of each iterative solution for the scalar flux (with the exception of the first) the following pointwise ratios are computed,

$$
\lambda^{k}(n)=\frac{\psi_{0}^{k-1}(n)}{\psi_{0}^{k}(n)}
$$

The iterative process is terminated on the $k-$ th iterate when

$$
\left|\left[\lambda^{k}(n)\right]_{\max }-I\right| \leq \epsilon
$$

and

$$
\left|\left[\lambda^{\mathrm{k}}(\mathrm{n})\right]_{\min }-I\right| \leq \epsilon
$$

where $\epsilon$ is an input parameter. In general, the proper choice for $\epsilon$ can be made only after gaining some experience with CLIP. In problems which have run so far, satisfactory results have been achieved by choosing $\epsilon$ equal to 0.00005 .

\section{BOUNDARY CONDITIONS}

\section{A. Origin}

At the origin, the directional flux should have conical symmetry about the axis of the cylinder. This requirement; if explicitly imposed, would force $\Psi_{2}, \psi_{3}, \psi_{4}$, and $\Psi_{5}$ to be equal to zero, and the solution at the origin would be overdetermined. To avoid this difficulty in CLIP, the first derivative with respect to $r$ of $\psi_{0}, \psi_{1}$, and $\psi_{2}$ are set equal to zero at the origin, and in addition the $1 / \mathrm{r}^{2}$ term in $\Sigma_{\mathrm{T} 2}$ is taken to be a very large but finite number. As a resul.t. of the presence of the $1 / r^{2}$ term and of the boundary condition which is imposed, $\psi_{2}, \Psi_{3}, \Psi_{4}$; and $\Psi_{5}$ become zero or very small in magnitude at the origin. 


\section{B. Interface}

The internal boundary conditions which must be satisfied if the moments are to be continuous (and also compatible with the iterative process) are

$$
\begin{gathered}
{\left[D_{0} \frac{d \psi_{0}^{k}}{d r}-D_{0} \frac{d \psi_{1}^{k}}{d r}+D_{0}\left(\frac{d}{d r}+\frac{2}{r}\right) \psi_{2}^{k}\right]_{+}=[]_{-}} \\
{\left[D_{1} \frac{d \psi_{1}^{k+1}}{d r}+\frac{D_{1}}{5} \frac{d \psi_{1}^{k}}{d r}-\frac{D_{1}}{5}\left(\frac{d}{d r}+\frac{2}{r}\right) \psi_{2}^{k}\right]_{+}=[} \\
{\left[D_{2} \frac{d \psi_{2}^{k+1}}{d r}-\frac{2 D_{2} \psi_{2}^{k+1}}{r}\right]_{+}=[}
\end{gathered}
$$

The symbols (-) and $(+)$ indicate the evaluation of the bracketed expression at the interface with quantities characteristic of the left- and right-hand medmium respectively. This convention will be adopted consistently throughout the remainder of the report.

\section{C.}

Strictly speaking, the concept of a cell as a repeating section of an infinfte lattice is, from a physical standpoint, a meaningless one in cylindrical geometry. One usually associates with a cell the property that there is no net flow of neutrons into or out of the cell, but aside from this there is no physical consideration which will select a unique set of boundary conditions. In CLIP, cell boundary conditions are taken to be

$$
\frac{d \psi_{0}}{d r}=0, \quad \frac{d \psi_{1}}{d r}=0 \text { and }\left(\frac{d}{d r}+\frac{2}{r}\right) \psi_{2}=0 \text {. }
$$

This particular choice guarantees that the reutron current is zero, and forces the gradient of the scalar flux to be zero. Conditions (17) differ from the conventional boundary conditions which are obtained by imposing reflecting symetry upon the directional flux. See Refs 4 and 5 for a discussion of cell boundary conditions in cylinarical geometry.

\section{Zero Flux}

In addition to cell problems CLIP will also solve reactor problems. The boundary condition which will be taken to correspond to this latter type of problem will be denoted as "Zero Flux"。 
It is not possible, in the general case, to terminate a reactor calculation at some finite radius by imposing boundary conditions. which. will be exact in incorporating the effect of the environment on the reactor. In practice however, a. reflector of sufficient size is usually present so that the calculation is relatively insensitive to the choice of boundary conditions. In diffusion theory, the scalar flux is chosen to be equal to zero. In CIIP it was found convenient to set $\psi_{0}, \psi_{1}$, and $\psi_{2}$ equal to zero. Thus the zero flux condition in CLIP may be considered as an extension of the zero flux condition which is employed in conventional diffusion codes such as WANDA.

\section{NUMERICAL SOLUTION}

In the interior of a region, the set of Eqs (13) is approximated at a mesh point, $n$, as,

$$
-D_{1}\left(\frac{\psi_{i, n+1}^{k}-2 \psi_{i, n}^{k}+\psi_{i, n-1}^{k}}{h^{2}}\right)-D_{1}\left(\frac{\psi_{i, n+1}^{k}-\psi_{i, n-1}^{k}}{2 h r_{n}}\right)+\Sigma_{T i, n} \psi_{i, n}^{k}=S_{i, n}^{k}
$$

Here $\psi_{i, n \div 1}^{k}, \psi_{i, n^{2}}^{k} \psi_{i, n+1}^{k}$ are the i-th moments at the $n-1, n, n+1$ mesh points respectively, belonging to the $k$-th iterate, and $h$ is the interval between mesh points. The $\mathrm{s}_{i, \mathrm{n}}^{\mathrm{k}^{\top}}$ are

$$
\begin{aligned}
& s_{0, n}^{k}=\ldots s_{n}-D_{0}\left[\begin{array}{c}
\frac{\psi_{1_{2} n+1}^{k}-2 \psi_{1_{2} n}^{k}+\psi_{1_{2} n-1}^{k}}{n^{2}}+\frac{\psi_{1_{2} n+1}^{k}-\psi_{1_{2} n-1}^{k}}{2 h r_{n}} \\
-\left(\frac{\left.\psi_{2, n+1}^{k}-2 \psi_{2, n}^{k}+\psi_{2_{2}, n-1}^{k}\right)}{n^{2}}-\frac{3}{2}\left(\frac{\psi_{2, n+1}^{k}-\psi_{2, n-1}^{k}}{h r_{n}}\right)\right.
\end{array}\right] \\
& s_{1, n}^{k}=\left(1+\frac{B_{1}}{5 D_{0}}\right) s_{n}-\frac{D_{1}}{5 D_{0}} s_{0, n}^{k-1}-\Sigma_{a} \psi_{0, n}^{k-1} \\
& \mathrm{~s}_{2, \mathrm{n}}^{\mathrm{k}}=-\frac{5}{4} \mathrm{~s}_{\mathrm{n}}-\frac{\Sigma_{1}}{4} \psi_{1, \mathrm{n}}^{\mathrm{k}}+\left(\frac{3}{5} \mathrm{D}_{1}+3 \mathrm{D}_{0}\right)\left(\frac{\psi_{1, n+1}^{\mathrm{k}} \psi_{I, n-1}^{\mathrm{k}}}{2 \mathrm{~h} \mathrm{r}_{\mathrm{n}}^{*}}\right) \\
& -\frac{3}{2} \frac{D_{0}}{r_{n}}\left(\psi_{0, n+1}^{k-1}-\psi_{0, r_{1}-1}^{k-1}\right)+\frac{5}{4} \Sigma_{a} \psi_{0 i, n}^{k-1}-\left(\frac{D_{1}}{10}+3 D_{0}\right)\left(\frac{\psi_{2, n+1}^{k-1}-\psi_{2, n-1}^{k-1}}{2 h r_{n}}\right)
\end{aligned}
$$

For notational simplicity; the $i$ and $k$ indices will hencerorth be suppressed. When there is a possibility for ambiguity they wlil be explicitly displayed. 
Equation (18) may be rewritten as

$$
\psi_{n+1}=k_{n} \psi_{n}-l_{n} \psi_{n-1}-m_{n}
$$

and by utilizing Stark's matrix inversion technique (Ref 6), the three point formula can be converted to the two point formula

$$
\psi_{n}=\frac{\psi_{n+1}+\beta_{n}}{\alpha_{n+1}}
$$

where

$$
\begin{aligned}
& \alpha_{n+1}=k_{n}-\frac{l_{n}}{\alpha_{n}}, \quad \beta_{n}=\frac{l_{n} \beta_{n-1}}{\alpha_{n}}+m_{n} \\
& k_{n}=\frac{\frac{2 D}{h^{2}}+\Sigma_{T n}}{g_{n}}, \quad l_{n}=\frac{\frac{D}{h^{2}}\left(1-\frac{h}{2 r_{n}}\right)}{g_{n}}
\end{aligned}
$$

and

$$
m_{n}=\frac{s_{n}}{g_{n}}
$$

with

$$
g_{n}=\frac{D}{h^{2}}\left(1+\frac{h}{2 r}\right)
$$

In order to reduce roundoff errors, the delta scheme, as used in WANDA (Ref 6), has been incorporated into CLIP. This consists in introducing the variables

$$
\delta_{n}=\alpha_{n}-1, \text { and } p_{n}=k_{n}-l_{n}-1=\frac{\Sigma_{T n}}{g_{n}} \text {. }
$$

An examination of the recursion relations will show that if the mesh width is very small, and if $\alpha$ is very close to one, then

$$
\alpha_{n+1} \approx 2+\frac{h^{2} \Sigma_{T n}}{D}-\alpha_{n} \text {. }
$$

From this it is clear that the full numerical significance of $\Sigma_{\text {Tn }}$ does not enter Into the calculation of $\alpha$. On the other hand, in the same situation

$$
\delta_{n+1} \approx \delta_{n}+\frac{h^{2} \Sigma_{T n}}{D} .
$$


Now $\delta$ is on the order of $h^{2}$, and thus a greater degree of numerical significance of $\Sigma_{\mathrm{Tn}}$ enters into the recursion relation. If the small mesh width persists for a good number of mesh intervals the error will be occumulative。 It has been found that the delta scheme reduces this type of error.

The relations applicable in the interior of a medium now become

$$
\Psi_{n}=\frac{\psi_{n+1}+\beta_{n}}{\left(1+\sigma_{n+1}\right)}
$$

where $\quad \delta_{n+1}=p_{n}+\frac{l_{n} \delta_{n}}{\left(1+\delta_{n}\right)}, \beta_{n}=\frac{l_{n} \beta_{n-1}}{1+\delta_{n}}+m_{n}$

Equations (25) through (26) are valid in the interior of a medium. We seek relations of this form which are valsd at the origin, at the interface between two media, and at the external boundary.

At the origin (in view of Section III $\sim A$ ) the set of Eqs (13) can be written

$$
-2 D_{i} \frac{d^{2} \psi_{i}^{k}}{d r^{2}}+\Sigma_{T i} \psi_{i}^{k}=s_{i}^{k}
$$

which in finite difference form become

$$
-\frac{4 D_{i}}{h^{2}}\left(\psi_{i, I}^{k}-\psi_{i, 0}^{k}\right)+\Sigma_{T_{i, 0}}^{k} \psi_{i, 0}^{k}=s_{i, 0}^{k}
$$

where

$$
\begin{aligned}
& s_{0,0}^{k}=s_{0}-\frac{4 D_{0}}{h^{2}}\left[\left(\psi_{1,1}^{k}-\psi_{1,0}^{k}\right)-2\left(\psi_{2,1}^{k} \cdots \psi_{2,0}^{k}\right)\right] \\
& s_{1,0}^{k}=\left(1+\frac{D_{1}}{5 D_{0}}\right) s_{0}-\frac{D_{1}}{5 D_{0}} s_{0,0}^{k-1}-\Sigma_{a} \psi_{0,0}^{k-1} \\
& s_{2,0}^{k}=-\frac{5}{4} s_{0}+\frac{5}{4} \Sigma_{a} \psi_{0,0}^{k-1}-\frac{3 D_{0}}{h^{2}}\left(\psi_{0,1}^{k-1}-\psi_{0,0}^{k-1}\right)-\frac{\Sigma_{1}}{4} \psi_{1,0}^{k} \\
& +\left(\frac{3}{5} D_{1}+3 D_{0}\right) \frac{2}{h^{2}}\left(\psi_{1,1}^{k}-\psi_{1,0}^{k}\right)-\left(\frac{D_{1}}{10}+3 D_{0}\right) \frac{2}{h^{2}}\left(\psi_{2,1}^{k-1}-\psi_{2,0}^{k-1}\right) \\
& \text { It follows then that } \delta_{i, I}=\frac{\Sigma_{T i, 0} h^{2}}{4 D_{i}} \text { and } \beta_{i, 0}^{k}=\frac{h^{2} S_{i, 0}^{k}}{4 D_{i}} \text {. }
\end{aligned}
$$


Now at an interface point, which will be denoted by the subscript $I$, the fictitious moments $\Psi_{I+1}^{*}$ and $\Psi_{I-I}^{*}$ are introduced which satisfy the following equations:

$$
\begin{aligned}
& \psi_{I+I}^{*}=\left[\mathrm{k}_{I}\right]_{-} \psi_{I}-\left[f_{I}\right]_{-} \psi_{I-I}-\left[\mathrm{m}_{I}^{*}\right]_{-} \\
& \psi_{I+I}=\left[x_{I}\right]_{+} \psi_{I}-\left[\mathcal{L}_{I}\right]_{+} \psi_{I-I}^{*}-\left[\mathrm{m}_{I}^{*}\right]_{+} \cdot
\end{aligned}
$$

Equation 30 (3z) defizes a continuation of the solution in the medium to the left (right) of the interfore linto the right (Ieft) as if the right (left) hand medium and right (Ieft) hand mesb. width did not asferer from the left (right).

It can be easily show that

$$
v_{I}=\frac{v_{I+I}^{*}+\beta_{I}^{*}}{I+\delta_{I+I}^{*}}, W_{I-I}^{*}=\frac{\psi_{I}+B_{I-I}^{*}}{I+\delta_{I}^{*}}
$$

where

$$
\begin{aligned}
& \delta_{I * I}^{*}=\left[p_{I}\right]^{-}+\frac{\left[f_{I}\right]^{\infty} \delta_{I}}{I+\delta_{I}}, \quad \beta_{I}^{* *}=\frac{\left[f_{I}\right]^{+} S_{I-I}}{I+\delta_{I}}+\left[m_{I}^{*}\right]^{*} \\
& \delta_{I+1}=\left[p_{I}\right]^{*}+\frac{\left[f_{I}\right]^{*} \delta_{I}^{*}}{1+\delta_{I}^{*}}, \quad \beta_{I}=\frac{\left[\ell_{I}\right]^{-} \beta_{I-I}^{*}}{I+\delta_{I}^{*}}+\left[m_{I}^{*}\right]^{*} .
\end{aligned}
$$

Notice that the $\left[m_{I}^{*}\right]^{*}$ cortsin dexivatives wishen are to be evaluated by the use of the fictitious noments. The anoner in which this is accomplished will be indicated later in this gection

The bourdary crossing conditions are glven by Eqs (14-16), Sec. III-B. The general form $1 \mathrm{~s}$

$$
\left[\frac{D d \psi}{\bar{d} r}-\frac{D c \psi}{r}-s\right]_{t}=[\quad]:
$$

The finite differeuce approxination to $\mathrm{Eq}(35)$ is then wrot then as

$$
\left[D\left(\frac{\psi_{I+1}-\psi_{I-1}^{*}}{2 h}\right)-\frac{D c \psi_{I}}{x_{I}}-s_{I}^{*} I_{t}=\left[D\left(\frac{\psi_{I+2}^{*}-\psi_{I-I}}{2 h}\right)-\frac{D c \psi_{I}}{r_{I}}-s_{I}^{*}\right] .\right.
$$

If now the fletitious moments in $\mathrm{Eq}(36)$ are replaced by their values as determined by Eqs (30) and (3I) and if $\|_{I-I}$ is replaced by $\frac{\psi_{I}+\beta_{I \infty I}}{I+\delta_{I}}$, then the desired relation at the interfaces cas be obtained. It is 


$$
\psi_{I}=\frac{\psi_{I+I}+\beta_{I}}{I+\delta_{I+1}}
$$

where

$$
\delta_{I+I}=p_{I}+\frac{l_{I} \delta_{I}}{I+\delta_{I}}, \quad \beta_{I}=\frac{l_{I}^{\beta} I-I}{I+\delta_{I}}+m_{I}
$$

with

$$
\begin{gathered}
p_{I}=\frac{\left[P_{I}\right]^{-}\left[l_{I}\right]^{+}+t\left[P_{I}\right]^{+}}{t\left(I+\left[l_{I}\right]^{+}\right)}, \quad l_{I}=\frac{\left[l_{I}\right]^{+}\left(I+\left[l_{I}\right]^{-}\right)}{t\left(I+\left[l_{I}\right]^{+}\right)} \\
m_{I}=\left(\left[M_{I}\right]^{-}+t\left[\frac{M_{I}}{l_{I}}\right]^{+}\right) \frac{\left[l_{I}\right]^{+}}{t\left(\left[l_{I}\right]^{+}+I\right)} \\
{\left[P_{I}\right]^{ \pm}=\left[p_{I}\right]^{ \pm} \mp\left[\frac{c D\left(2 r_{I} \mp h\right)}{h_{I}^{2}}\right]^{ \pm}} \\
{\left[M_{I}\right]^{ \pm}=\left[m_{I}^{*}\right]^{ \pm} \mp\left[\frac{(2 r \mp h) D s_{I}^{*}}{h r_{I}}\right]^{ \pm}} \\
t=\frac{\left[\frac{D}{h}\right]^{+}}{\left[\frac{D}{h}\right]^{-}}
\end{gathered}
$$

It now remains to determine $\delta$ 's and $\beta$ 's such that the external boundary conditions are satisfied. We distinguish the outer boundary mesh point with the subscript $B$.

The zero flux condition is trivial and results simply in

$$
\psi_{B-1}=\frac{\beta_{B-I}}{I+\frac{1}{\delta_{B}}} .
$$

The ccll conditions, which are given by Eqs (17), can be written as

$$
\frac{d \psi}{d r}+\frac{c^{\prime} \psi}{r}=0 \text {, }
$$

and in finite difference form become

$$
\frac{\psi_{B+1}^{*}-\Psi_{B-1}}{2 h}+\frac{c^{\prime} \Psi_{B}}{r_{B}}=0
$$

where

$$
\psi_{B+1}^{*}=k_{B} \psi_{B}-l_{B} \psi_{B-1}-m_{B}^{*} \text {. }
$$


Now if

$$
\psi_{B}=\frac{\psi_{B+1}^{*}+B_{B}^{*}}{1+\delta_{B+1}^{*}}
$$

then

$$
\delta_{B+1}^{*}=p_{B}+\frac{l_{B} \delta_{B}}{I+\delta_{B}}, \quad \beta_{B}^{*}=\frac{l_{B} \beta_{B}-I}{I+\delta_{B}}+m_{B}^{*}
$$

With the aid of the preceding relations it can be easily shown that

$$
\Psi_{B}=\left(\beta_{B}^{*}+\frac{\beta_{B-1}}{1+\delta_{B}}\right) /\left(\delta_{B+1}^{*}+\frac{\delta_{B}}{1+\delta_{B}}+\frac{c^{\prime}}{r_{B}}\right) .
$$

The numericai solution is thus achieved as roliows. At any point in the iterative cycle one always has availabie

$$
\psi_{j, n^{2}} \psi_{j, I+I^{2}}^{*} \psi_{j, I-I}^{*} \psi_{j, B^{2}} \psi_{j, B+I}^{*}
$$

from which $m_{i, n}, m_{i, I}$, and $m_{i, 3}$ can be constructed. One then calculates the $\delta$ 's and the $\beta^{\prime}$ 's associated with the intexnel and external points, and proceeds to calculate the $i-t h$ moment by means of Eas $(46)$, (or itl), (37), (20). The solution for each moment $i$, for each iteration is obtained in an identical fashion. The process is. terminated wher the convergence criteria has yeen satisfied, or when a specified number of iterations have been completed.

Since the $S_{i}$ contaix derivatives of the moments, loss of numerical significance can result if these derivatives are evaluated straightforwardiy by standard differencing techniques in sitiations where the moments vary little from one mesh point to another. To avoid this, a refinement is introduced into the calculation of these derivatives. At a point $n$, these derivatives would ordinarily be evaluated by terms of the form

$$
\psi_{n+1}=\psi_{n-1} \text { and } \psi_{n+1}-2 \psi_{n}+\psi_{n-1}
$$

Now if

$$
\gamma_{n}=\psi_{n+1}-\psi_{n}
$$

then expressions (48) can be rewritten as

$$
\gamma_{n}+\gamma_{n-1} \text { and } \gamma_{n}-\gamma_{n-1}
$$

respectively。 
Rather than evajuste $y_{n}$ by means of Eq (49), we introduce the 8 's and $\beta^{i}$ 's such that

$$
\gamma_{n}=\frac{\psi_{n+1} \delta_{n+1}-\beta_{n}}{1+\delta_{n+1}}
$$

An inspection of (51) will show that $y_{n}$ is being computed to a greater degree of significance than a computation of $\gamma_{n}$ by (49) when either $\mathrm{h}$ is small or $\delta$ is smalz.

Thus at points interior to a mediun, $y_{y_{i}}$ is computed by means of $\mathrm{Eq}$ (5I). Similariy,

$$
\begin{aligned}
& \gamma_{I}^{*}=\psi_{I+1}^{*}-\psi_{I}=\delta_{I+1}^{*} \psi_{I}-\beta_{I}^{*} \\
& \gamma_{I-I}^{*}=\psi_{I}-\psi_{I-I}^{*}=\frac{\delta_{I}^{*} \psi_{I}-\beta_{I-I}^{*}}{1+\delta_{I}^{*}} \\
& \gamma_{B}^{*}=\psi_{B+1}^{*}-\psi_{B}=\delta_{B+I}^{*} \psi_{B}-\beta_{B}^{*} .
\end{aligned}
$$

\section{FREPARATION OW TNETII}

\section{A. General Descristion}

Input to the CIIP I program consists of a title card, control information, a description of the geometry, pointwise or regionwise sources, and cross sections for each region. Each tipe of data is lientified by a series numer ranging from 10000 to 60000 .

\section{B. Description of Serieas}

\section{Title Card}

Columin I-67 are avaijeble for problem laentiplcation

Colurans $58-72$. must contain CLIP 1 .

2. Card 10000

a. Muiber of regions $(\leq 50)$.

b. Numler of pointo $(5501)$, with the rrigin counted as point number one.

c. Right-hand boundary condition ( $0=$ zero flux, $I$ = zero gradient).

d. Type of input source $(0$ = regionwise, 1 = polntwise).

e. Naximum number of iterations the problem is to run. Use a zero if the problem is to run untii it converges.

f. Number of fuel regions. Ise a zero if there are no fuel regions specifled. The purpose for specifying fuel regions is to obtain an edit of:

$$
\sum_{\text {fuel regions }} \int \psi_{0} r d r \text { and } \sum_{\text {fuel regions }} \vec{z}_{a} \int \psi_{0} \text { rdr. }
$$


If fuel regions are not specified this edit will be omitted.

go Convergence criterion (a floating point number).

3. $\operatorname{card}(\mathrm{s}) \cdot 20000$

This series contains, in order, the region numbers of the fuel regions.

4. $\operatorname{card}(\mathrm{s}) \quad 30000$

This series contains, in order, the interface point numbers. The last number must be the outer boundary, and all numbers must be odd.

5. Card(s) 40000

This series contains the mesh spacing for each region.

6. Card(s) 50000

This series contains the regionwise sources. If regionwise sources are not to be specified, this series must not be used.

7. $\operatorname{Card}(\mathrm{s}) 51000$

This series contains the pointwise sources. At an interface, list only the source which is dependent on the region to the left. If pointwise sources are not specified, do not use this series.

8. $\operatorname{Card}(\mathrm{s}) 52000$

This series contains those interface sources which are dependent on the region to the right of the interface.

9. $\operatorname{Card}(\mathrm{s}) 60000$

This series contains the cross sections for each region. There wlll be one card for each region containing $\Sigma_{\mathrm{a}}, \Sigma_{\mathrm{so}}, \Sigma_{\mathrm{s} l}, \Sigma_{\mathrm{s} 2^{\prime}}, \Sigma_{\mathrm{s} 3^{\circ}}$

10. Format

a. Card numbers must start in column one.

b. Each piece of dota is separated from the next by a comma. The last number on a card must not be followed by a comma.

c. The first blank column on a card indicates the end of data for that card.

d. Columns 1-72 are available for data.

e. If it is necessary to continue the data within a series on additional cards, these cards must be numbered consecutively, i.e. 60000, 60001, etc.

fo The following parameters must be integers: all control parameters appearing on card 10000 except for the convergence criterion, interface numbers, and fuel region numbers. These numbers must not contain a decimal point.

g. All other data must be in floating-point form. There are several ways of expressing a floating point number. The value 0.001234 may be written as 0.001234 , or $0.1234 \mathrm{E}-2$.

\section{DESCRIPTION OF OUTPUT}

The following information will be edited for each problem:

1. A listing is made of the data deck.

2. The calculated group parameters, $D_{i}$ and $\Sigma_{T_{i}}$ are printed。 3. Values for $\lambda_{\max }$ and $\lambda_{\min }$ will be printed after each iteration except the
first. 
4. The point number, radius, and fluxes will be printed after convergence has taken place or after the problem has been stopped after a given number of iterations.

5. The width of each region is listed.

6. The following integrals calculated over each region by Simpson's Rule, will be printed:

a. $\int \Psi_{0} r d r$

b. $\int \operatorname{srdr}$

c. $\Sigma_{a} \int \psi_{0} r d r$

7. Balance checks are printed. A comparison of the following values should give some estimate of the adequacy of the mesh spacing.

a. $\left.r \psi_{3}\right|_{b} ^{B}=\int_{b}^{B}\left(s-\Sigma_{a} \psi_{0}\right) r d r$

where

$r_{n} \psi_{3, n}=D_{0}\left\{r_{n}\left[\frac{\psi_{1, n+1}-\psi_{1, n-1}}{2 h}-\frac{\psi_{2, n+1}-\psi_{2, n-1}}{2 h}-\frac{\psi_{0, n+1}-\psi_{0, n-1}}{2 h}\right]-2 \psi_{2, n}\right\}$

b. $\left.\quad r \Psi_{4}\right|_{b} ^{B}=\frac{1}{3} \int\left(s-\Sigma_{a} \psi_{0}-\Sigma_{1} \Psi_{1}\right) r d r$

where

$$
\begin{aligned}
r_{n} \Psi_{4, n} & =-\frac{D_{1}}{5}\left\{r_{n}\left(\frac{\Psi_{1, n+1}-\Psi_{1, n-1}}{h}\right)-\frac{r_{n}}{3}\left(\frac{\Psi_{2, n+1}-\Psi_{2, n-1}}{2 h}-\frac{2}{3} \Psi_{2, n}\right\}\right. \\
\text { c. }\left.\quad r^{3} \Psi_{5}\right|_{b} ^{B} & =\frac{4}{3} \int_{b}^{B} r^{3}\left[s_{2}-\left(\frac{D_{1}}{5}+6 D_{0}\right)\left(\frac{\Psi_{2}}{r^{2}}\right)-\frac{5}{2}\left(\Sigma_{a}+\Sigma_{s}-\Sigma_{s 2}\right) \Psi_{2}\right] d r
\end{aligned}
$$

where

$$
r_{n}^{3} \psi_{5, n} \equiv-\frac{4}{3} D_{2} \cdot r_{n}^{3}\left[\frac{\psi_{2, n+1}-\psi_{2, n-1}}{2 h}-\frac{2}{r_{n}} \psi_{2, n}\right]
$$

VII. OPERATIING INSTRUCTIONS.

\section{A. Printer Board: AFROJET \\ B. Tapes:}

1. Logical number I - BCD input tape. Th1s tape is not used if the input data is on cards.

2. Logical number 5 - output tape. 
C. Sense Switches:

1. Number 1 - down for BCD card input, normal for BCD tape input.

2. Number 5- normal except when the operator desires an on-line monitor of the convergence. With this sense switch depressed, which may be done at any time during the running of the problem, values of $\lambda_{\max }$ and $\lambda_{\min }$ are printed on-line after each iteration. Each of these parameters must be approaching unity if the problem is to converge.

D. Console: CLEAR, IOAD CARDS

E. Card Reader: START

Any number of consecutive problems may be run either from cards or BCD tape. One blank card must be inserted after each problem.

F. Transfer of Control:

If desired, control may be transferred to the beginning of the program by manually executing a transfer to $140_{8^{\circ}}$ 


\section{REFERREITCES}

1. J. Fleck, "The $\psi^{3}$ Approximation with Anisotropic Effects for Cylindrical Geometry", BNL-1574. (January 1953)。

2. W. W. Clendenin and H. Go Gelbard, "BOUND I, 2, 3 - IBM-704 Programs for the Analytic Solution of the One Energy P-3 Approximation in Cylindrical Geometry", WAPD-TM-303 (November 1961)。

3. B. L. Anderson, J. A. Davis, E. M. Gelbard, P. H. Jarvis, "FLIP - An IBM-704 Code to Solve the $\mathrm{P}_{\mathrm{I}}$ and Double $\mathrm{P}_{\mathrm{I}}$ Equations in Slab Geometry", WAPD-TM-134: (March 1959).

4. J. A. Tìe, Nuclear Science and Engineering 9, 286 (1961).

5. W. W. Clendenin, "Cell Boundary Conditions in Cylindrical Geometry", (tö' be' published in Nuc. Sci. and Eng.).

6. 0. J. Marlowe, C. P. Saalbach, L. M. Culpepper, D. S. McCarty, "WANDA A. One-Dimensional Few-Group Diffusion Equation Code for the IBM-704", WAPD-TM-28: (November 1956)。 